REVISITING STAR STUDIES 


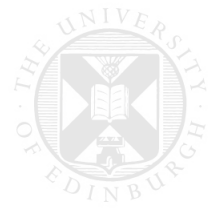

EDINBURGH
University Press

Not for distribution or resale. For personal use only. 


\title{
REVISITING STAR STUDIES
}

\section{Cultures, Themes and Methods}

\author{
Edited by \\ Sabrina Qiong Yu and Guy Austin
}


Edinburgh University Press is one of the leading university presses in the UK. We publish academic books and journals in our selected subject areas across the humanities and social sciences, combining cutting-edge scholarship with high editorial and production values to produce academic works of lasting importance. For more information visit our website: edinburghuniversitypress.com

(C) editorial matter and organisation Sabrina Qiong Yu and Guy Austin, 2017

(C) the chapters their several authors, 2017

Edinburgh University Press Ltd

The Tun - Holyrood Road

12 (2f) Jackson's Entry

Edinburgh EH8 8PJ

Typeset in 10/12.5 pt Sabon by

Servis Filmsetting Ltd, Stockport, Cheshire

and printed and bound in Great Britain by

CPI Group (UK) Ltd, Croydon CR0 4YY

A CIP record for this book is available from the British Library

ISBN 9781474404310 (hardback)

ISBN 9781474404327 (webready PDF)

ISBN 9781474404334 (epub)

The right of the contributors to be identified as authors of this work has been asserted in accordance with the Copyright, Designs and Patents Act 1988 and the Copyright and Related Rights Regulations 2003 (SI No. 2498). 